\title{
$\mathrm{PH} 103$ acualidad
}

\section{Acción artística y saber tradicional se unen en un proyecto para revitalizar hórreos y paneras en Asturias}

\begin{abstract}
"Hacia una ciudadanía agropolitana" es el nombre de la propuesta que se inauguró a finales de marzo de este año. Consiste en una serie de acciones artísticas, paisajísticas y experienciales, para llevar a cabo a lo largo de 2021, en torno a los hórreos y paneras de las aldeas de Trubia y Veranes (Gijón, Asturias). El proyecto, seleccionado en la convocatoria Art for Change de La Fundación La Caixa, mezcla pedagogía y práctica artística, saberes tradicionales con maneras de hacer desarrolladas desde la creación artística contemporánea. Eremitorios agropolitanos para tiempos desasosegados.
\end{abstract}

Virginia López Fernández | PACA_proyectos Artísticos Casa Antonino

URL de la contribución <http://www.iaph.es/revistaph/index.php/revistaph/article/view/4838>

Hoy los hórreos, cabazos y paneras en Asturias, incluso siendo objeto de protección por parte de la administración ${ }^{1}$ por sus valores materiales (interesante ejemplo de la arquitectura tradicional) e inmateriales (ejemplo de modos de vida y usos), se vacían y derrumban. Son "monumento" absolutamente contemporáneo, testimonio material y silencioso de una realidad sin resolver: las relaciones campo-ciudad y nuestra propia relación con el territorio.

Por este motivo, y como continuación del proyecto Habitantes Paisajistas: Tierra adentro (realizado en 2019 en colaboración con el museo arqueológico Villa Romana de Veranes), a lo largo del 2021 se pone en marcha Hacia una ciudadanía agropolitana, proyecto seleccionado en la convocatoria Art for Change de la Fundación La Caixa, en colaboración con LABoral y con el apoyo de Impulsa (Ayuntamiento de Gijón) ${ }^{2}$ en torno a los hórreos y paneras de las aldeas de Trubia y Veranes (zona rururbana de Gijón).

Hórreos y paneras en Asturias son graneros sobre-elevados en el terreno sobre poyos (pilares), cajas de madera un tiempo recolectoras de la cosecha, pero también con otras muchas funciones simbólicas, rituales... un verdadero tesoro del patrimonio asturiano, del paisaje agrario y de "la aldea perdida". En este proyecto se exploran algunas de las muchas significaciones o usos de estas construcciones, hoy silenciosas y a la espera de nuevas lecturas y afectos.
La panera es ejemplo y metáfora de adaptación, vitalidad, reactivación, de espacio común, de valores como la reciprocidad o la responsabilidad compartida. Conceptos y valores que deberían estar siempre asociados a nuestra idea de patrimonio. Porque, como afirma Octavio Paz, toda novedad tiene al menos 100 años: es cuestión de reinterpretar o resignificar aquello que ya forma parte de nuestro patrimonio y herencia cultural. Como en una melodía con variaciones, donde el bajo continuo no se interrumpe.

Además, en hórreos y paneras se dan una serie de encuentros y equilibrios de los que aprender:

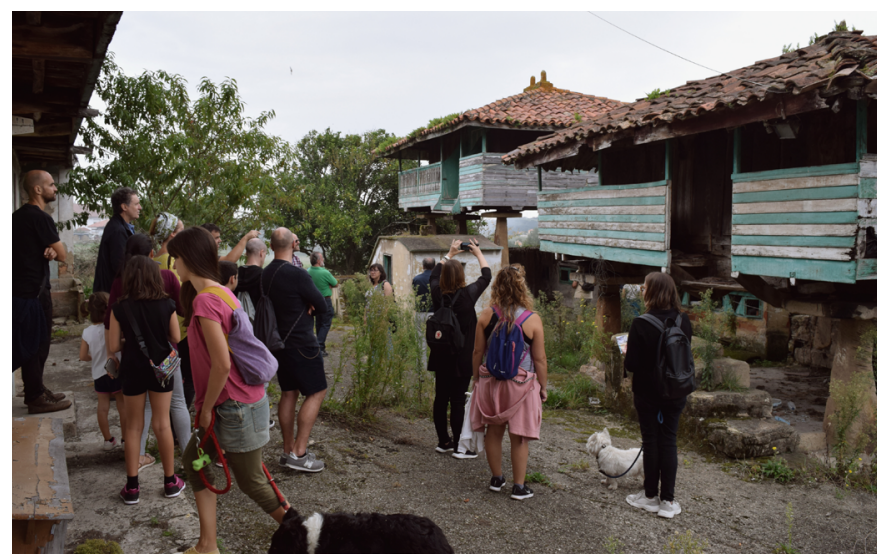

Paseo con Joaco López y Cristina Cantero por hórreos y paneras de Cenero (Tierra adentro, 2019) | foto Virginia López Fernández 


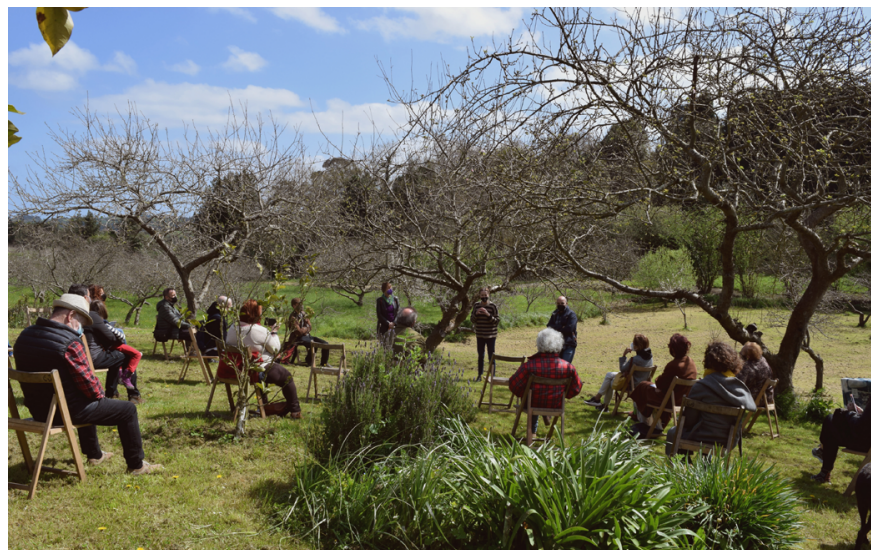

Presentación del proyecto Hacia una ciudadanía agropolitana (PACA. 27 marzo de 2021) | foto Giovanni Lanterna

Arraigados a la tierra, son móviles y se elevan al cielo, estamos como suspendidos. Son oscuras cajas de madera en su interior, pero se abren al paisaje que las circunda por puertas y ventanucos, el contacto dentro-fuera es constante a través de una penumbra germinal. Son silenciosas, pero actúan como cajas de resonancia. Son cabañas para pensar y refugio, un espacio íntimo, un eremitorio, aunque debajo de ellas el espacio abierto ha sido siempre espacio de socialización. Por tanto, un juego constante entre lo comunitario y lo personal, la penumbra y la luz, la reflexión y la producción, el contacto y la distancia, lo funcional y lo lúdico, lo terrenal y lo espiritual. Una serie de equilibrios difíciles de mantener en el mundo actual que exige exposición constante, rendimiento, visibilidad, dinamismo. Como antídoto, esta propuesta cree en la necesidad de repensar las políticas culturales de manera que se camine hacia verdaderos ecosistemas culturales difusos en los territorios frente a la actual tendencia urbano-céntrica y centrifugadora que, cada vez más, produce desasosegados digitales, clones hiperactivos y desarraigados.

En este proyecto las obras son un instrumento y no un fin. La intención es facilitar en el "hacer" la activación de procesos de interrogación e integración en varias direcciones: creación artística-mediación, saberes formales-informales, modernidad-tradición, agro-cultura, creación-investigación, intelecto-sentimiento. Se usarán metodologías propias del agro asturiano: filandón y reciprocidad (entre artistas y comunidad local), "andecha" o trabajo compar-

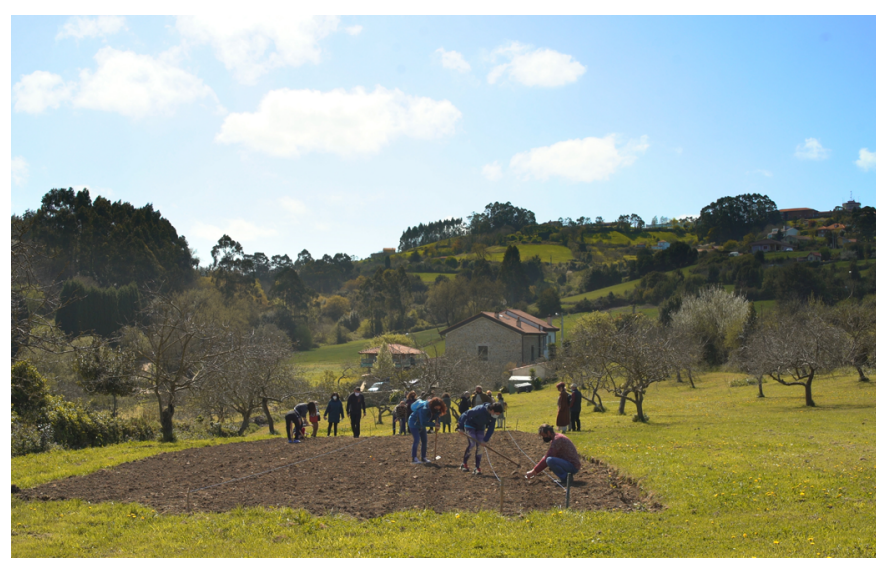

Siembra colectiva de hierba pastel (isatis tinctorea) (PACA. 27 marzo de 2021) | foto Nadia Penella

tido, tiempos largos y repetitivos, relacionando procesos creativos, ciclos agrícolas y naturales, manualidad, saber artesano, la memoria y honestidad de los materiales y técnicas tradicionales en combinaciones inesperadas.

El proyecto se inauguró el pasado 27 de marzo con una siembra colectiva de isatis tinctorea en $\mathrm{PACA}^{3}$. A partir del 10 de abril dieron inicio los encuentros, paseos y talleres (abiertos y gratuitos) que se realizarán de forma ininterrumpida hasta el 28 de agosto. Los procesos activados y las obras realizadas junto a las personas participantes serán motivo de una exposición final en LABoral Centro de Arte (Gijón) a partir de octubre de 2021.

Todas las actividades mantienen un "hilvanado" y las hemos agrupado en cinco capítulos:

$>$ De la planta al color. Tierra, pucheros y sol (mar zo-agosto)

Tras la siembra de isatis tinctorea (planta de la que se extrae el color azul pastel para el teñido de tejidos) en diferentes encuentros aprenderemos el proceso de extracción del pigmento a partir de sus hojas y haremos talleres de tintura. El objetivo final: la creación colectiva de una colcha-vestido compuesta por fragmentos realizados por cada participante. Esta pieza se nutrirá de las "recolecciones" a través de talleres de fotografía con la técnica de la cianotipia. Vestidos celestes-mantos florales, cobijo azul animado por nuestros cuerpos e historias. 
$>$ Pitos y flautas (abril-junio)

De la mano de Daniel Franco y Fernando Oyágüez exploraremos las posibilidades sonoras de nuestro aparato fonador buscando relaciones con el movimiento y el espacio, ahondando en el paisaje interno del hecho corporal y sus vinculaciones emocionales y afectivas. Un paso más allá trabajaremos sobre las palabras y los relatos, comprendiéndolos en acciones y recorridos que nos permitan realizar partituras o protocolos generadores de nuevas acciones y significados. Por otra senda, realizaremos ejercicios de escucha atenta y paseos sonoros y a través de objetos conformaremos instrumentos que amplíen el ámbito de la comunicación, la escucha, la espera y el encuentro. Con todas las ideas surgidas y los materiales registrados, realizaremos un concierto en la aldea de Trubia y el grupo pensará el formato para una intervención final en los espacios de LABoral Centro de Arte.

$>$ Recolectores (abril-julio)

Entre abril y mayo documentaremos, con fotos y dibujos, los motivos decorativos pintados y tallados en las paneras y hórreos del entorno. En junio, recolectaremos plantas y cultivos locales que se prensarán y secarán, a través de paseos etnobotánicos de la mano de Lorena Lozano (Econodos). Estos materiales servirán para la elaboración de negativos en los talleres de fotografía. Una visita al Muséu del Pueblu d'Asturies servirá para contextualizar nuestras recolecciones. El taller de papel con el maestro papelero Juan Barbé nos ayudará a experimentar con papeles artesanos a partir de fibras vegetales.

$>$ Kit de herramientas y aperos inútiles (agosto)

A partir de las experiencias compartidas, Grigri Projects (Susana Moliner y David Pérez) nos guiará en la creación de materiales pedagógicos. El objetivo es extraer de todos los procesos y acervos activados, herramientas útiles y "aperos inútiles" para su aplicación y manipulación en el ámbito escolar de unas ciudades, hoy por hoy, huérfanas de campo. Cinco días de encuentros y talleres para imaginar y crear nuestra caja de herramientas.
$>$ Filandones (agosto)

Los días de agosto son siempre buenos para compartir tiempo y experiencias bajo la sombra de un manzano o debajo de la panera. En diferentes sesiones y turnos, PACA estará abierta a la realización colectiva del manto-vestido, jornadas de cosido y relatos compartidos. Colabora en esta fase Galiana, mezclando lo lúdico y lo mágico con el hacer minucioso y práctico.

La propuesta forma parte de una línea de trabajo de LABoral Centro de Arte titulada Reset Rural, que quiere contribuir a la creación colectiva de nuevas dinámicas colaborativas entre cultivo y cultura, entre el campo y la ciudad, en línea con los objetivos de la Agenda 2030. Todas las actividades son gratuitas y el único requisito para participar es cultivar la curiosidad y sentir que todas sumamos dentro un proyecto común de creación y aprendizajes compartidos.

\section{NOTAS}

1. Decreto 449/1973, de 22 de febrero (BOE, n. ${ }^{\circ}$ 62, de 13 de marzo de 1973).

2. Junto a Virginia López (autora del proyecto) colaboran Daniel Franco, Fernando Oyágüez, Lorena Lozano (Econodos), Susana Moliner y David Pérez (Grigri Projects), Galiana, Cristina Cantero, Massimo Baldini (Tintúra), Juan Barbé (Eskulan), Muséu del Pueblu d'Asturies y la Asociación de Vecinos de Cenero "Los 16".

3. Proyecto centrado en las artes contemporáneas, las prácticas ambientales, comunitarias y la educación artística con programas de residencias artísticas internacionales. Nace en 2013 como artist run space, por iniciativa de la artista Virginia López, en una antigua "casería" de la zona rural de Gijón (España), Casa Antonino (con su casa, panera, llagar, terreno de cultivo y pomarada). 